\title{
Vorsorgen und rechtzeitig behandeln
}

\begin{abstract}
Entscheidend ist die Früherkennung - das gilt besonders für das Bronchuskarzinom. Während die Heilungsrate im Frühstadium ohne Metastasen durch die chirurgische Therapie sehr hoch ist, beträgt das Einjahresüberleben bei Diagnose im fortgeschrittenen Stadium lediglich 30 bis 40 Prozent. Sehr oft, aber nicht immer, ist Rauchen die Ursache für Lungenkrebs. Das Geschlechterverhältnis der Betroffenen gleicht sich immer mehr an. Im Rahmen des Lungenkrebsvorsorgemonats im November wurde der aktuelle Stand der Entwicklungen im Bereich der Therapie präsentiert.
\end{abstract}

In Österreich erkranken jedes Jahr etwa 4600 Personen neu an Lungenkrebs, 3600 Menschen versterben jährlich an der Erkrankung. Mögliche weitere Ursachen neben dem aktiven Rauchen können auch Passivrauchen, Radonstrahlung, Asbest und andere Chemikalien sowie Luftverschmutzung sein. Während lang andauernder Husten, Brustschmerzen und blutiger Auswurf laut einer Umfrage häufig mit einer möglichen bösartigen Erkrankung in Verbindung gebracht werden, schätzten die Befragten Symptome wie Gewichtsverlust, Appetitlosigkeit, Heiserkeit und Schwäche als eher harmlos ein und stellten keinen Zusammenhang mit einer möglichen Lungenkrebserkrankung her. Männer sind hier übriQuelle: Medien-Workshop Bristol-Myers Squibb: Lungenkrebs und die Zukunft der Immunonkologie, Wien, 19. Oktober 2016
Bronchuskarzinom (NSCLC) mit etwa 85 Prozent und das kleinzellige Bronchuskarzinom (SCLC) mit etwa 15 Prozent die häufigsten, wobei, so Univ.-Prof. Dr. Christoph Zielinski, Univ.-Klinik für Innere Medizin I, Medizinische Universität Wien, das SCLC besonders schnell wächst. Zielgerichtete Therapien, die bei bestimmten Mutationen einsetzbar sind, und vor allem die Immuntherapie konnten in den vergangenen Jahren große Fortschritte in der Behandlung erreichen, berichtete Zielinski. Grundsätzlich ist das Bronchuskarzinom mit seiner hohen Mutationsrate besonders schwierig zu therapieren, das es dadurch relativ schnell zu Resistenzentwicklungen kommt. Besonders das NSCLC ist von einer der höchsten Mutationsraten bei allen Krebserkrankungen gekennzeichnet, wobei Rauchen einer der Hauptgründe für diese hohe Veränderlichkeit sowohl beim NSCLC als auch beim SCLC sein könnte. Diese hohe Mutationsrate wiederum könnte zur hohen Neo-Antigen-Expression führen.

Große Erwartungen setzt man in der Therapie des fortgeschrittenen NSCLC derzeit auf die Immuntherapie. Das Immunsystem des Menschen strebt grundsätzlich danach, bösartige Zellen durch vielfältige Mechanismen zu eliminieren. Dazu zählen auch die Bildung von tumorspezifischen T-Zellen und die Aktivierung der T-Zell-Immunantwort. Im Falle eines Krankheitsausbruchs gelingt es den Tumorzellen allerdings, die Immuncheckpoint-Mechanismen für ihre Proliferation ausznützen und das Immunsystem damit außer Gefecht zu setzen. Die Immuntherapie zielt nun auf die zentralen Mediatoren der Immun-
checkpoint-Signalwege ab, zu denen das „programmed Cell Death Protein“ PD-1 - und dessen Liganden PD-L1 und PD-L2 zählen. Diese Checkpoint-Inhibitoren inhibieren die körpereigene Abwehr durch T-Zellen indem sie die vom Tumor verursachte Immun-Blockade aufheben. „Der nächste Schritt", so Zielinski, , sind Kombinationstherapien, die in ersten Studien auf verbesserte Überlebensraten hinweisen." Dabei bestehen verschiedene Möglichkeiten von Kombinationen, die auf einer aktiven Immuntherapie aufbauen: Chemotherapie, Strahlentherapie, zielgerichtete Therapie oder eine zusätzliche andere Immuntherapie. Mehrere T-Zell-Targets bieten sich für die Immuntherapie an, dabei könnten agonistisch wirksame Antikörper ko-stimulierende Moleküle aktivieren und ko-inhibierende Moleküle blockieren, die die T-Zell Stimulation verstärken, um die Tumorzerstörung zu fördern.

\section{Kampagne mit Jack Huston für mehr Aufmerksamkeit} Mit der 2016 gestarteten Kampagne "Lungenkrebsvorsorge im Rampenlicht" mit dem britischen Schauspieler Jack Huston möchte Bristol-Myers Squibb Patienten und deren Angehörige über die Erkrankung besser informieren. Informationen zu Vorsorge und Diagnose: www.lungenkrebsvorsorge.at

$k i$

Wien klin Mag 2016 · 19:218 DOI 10.1007/s00740-016-0150-1 Online publiziert: 23. November 2016 ๑) Springer-Verlag Wien 2016 